\title{
Lever biting as an avoidance response
}

\author{
PHILIP N. HINELINE and JAMES F. HARRISON \\ Temple University, Philadelphia, Pennsylvania 19122
}

\begin{abstract}
Lever biting was not supported in three rats for which this was the only response that could postpone shock. Four naive rats for which both lever biting and leverpressing could postpone shock consistently pressed the lever, as in conventional Sidman procedures where leverpressing is the only effective response. Two of the four rats bit the lever many times during some sessions, but this did not appear to be controlled by the avoidance contingencies. When only lever biting could postpone shock, the two rats' lever biting increased, but not sufficiently to avoid as many shocks as they previously avoided by leverpressing. These results advise caution in assigning a major role to defense reactions, such as shock-induced attack, in the acquisition of avoidance.
\end{abstract}

The role of species-specific behavior in avoidance has become a major theme in discussions of avoidance conditioning. Much of the interest in this issue is traceable to Bolles's influential arguments (Bolles, 1970, 1971) that such behavior plays a pivotal role in the acquisition of avoidance. In brief, Bolles (1971) argued that certain classes of responses are predisposed to occur with high probability in situations where shocks frequently occur. $\mathrm{He}$ proposed, further, that species-specific defense reactions (SSDRs) directly induced by shock are the only learnable responses in avoidance situations. It follows from this that response topographies that overlap with an SSDR should be easily learned, while response topographies that are very different from an SSDR should be difficult, if not impossible, to learn as avoidance responses. Bolles (1971) contended that, "Although data are lacking, it seems that it would be easy to teach the rat an avoidance response that was compatible with attack or offensive behavior" (p. 219).

It would appear that these notions could be tested through study of biting responses. First, biting appears to satisfy Bolles's definition of an SSDR; it is clearly compatible with attack or offensive behavior. Further, there is abundant evidence that electrick shock, an ubiquitous feature of avoidance experiments, induces biting. For example, biting responses upon presentation of footshock have been observed in rats (e.g., Ulrich \& Azrin, 1962) and monkeys (e.g., Azrin, Hutchinson, \& Hake, 1963). These responses have been directed toward conspecifics (Azrin, Hutchinson, \& Hake, 1967; Ulrich \& Azrin, 1962) and toward inanimate aspects of the experimental environment (Azrin, Hutchinson, \& Sallery, 1964; Azrin et al., 1967; Azrin, Rubin, \&

The research reported here was accomplished with support of PHS Research Grant MH-18432 from the National Institute of Mental Health to the senior author. Reprints can be obtained from the senior author, Department of Psychology, Temple University, Philadelphia, Pennsylvania 19122. James F. Harrison's current address is Bell Telephone Laboratories, Crawfords Corner Road, Holmdel, New Jersey.
Hutchinson, 1968; Hutchinson, Azrin, \& Hake, 1966; Pear, Moody, \& Persinger, 1972).

Pear et al. (1972) provided quantitative measures of lever biting during avoidance conditioning of a freeoperant leverpress response. Reporting substantial amounts of lever biting, they suggested that since shock-elicited attack can be directed toward inanimate aspects of the environment, lever biting might occur and be recorded as leverpresses in experiments where leverpressing had been designated as the avoidance response. Elicited biting might thus be mistaken for operant behavior in these experiments. On the other hand, in line with (and preceding) Bolles's arguments, Azrin et al. (1964) suggested that such biting responses directed toward the manipulandum in avoidance conditioning procedures might be a significant factor in the acquisition of operant leverpressing in rats and monkeys. Azrin et al. (1967) provided some evidence that supports this position when they obtained rapid acquisition of avoidance in a squirrel monkey, using a hose-biting response.

Since Bolles has also suggested that the leverpress is a response somewhat resistant to avoidance conditioninghaving relatively little overlap with SSDRs-the present experiment was undertaken to assess the relative ease with which lever biting and leverpressing could be acquired and maintained as avoidance responses in the rat. The apparatus and shock intensity were similar to those used by Pear et al. (1972) in their study of shock-elicited biting.

\section{METHOD}

\section{Subjects}

Seven experimentally naive male rats weighing approximately 250-300 $\mathrm{g}$ at the outset of experimentation served as subjects. Five (B-1, B-2, B-3, B-4, and B-5) were hooded (Long-Evans) rats, while the remaining two (B-7 and B-8) were albino rats of the Sprague-Dawley strain. All animals were housed individually and given free access to food and water at all times other than the experimental sessions. 


\section{Apparatus}

A conventional operant conditioning chamber was used. It was $20.3 \times 23.5 \times 19 \mathrm{~cm}$, with clear plastic sides and ceiling, aluminum end walls, and a grid floor (bars of 4-mm diam, spaced $1.4 \mathrm{~cm}$ apart, center to center). The response lever was an exact replica of the one described by Pear et al. (1972), being designed to detect both leverpressing and lever biting. It was $5 \times 1.3 \mathrm{~cm}$, extending $2.1 \mathrm{~cm}$ into the chamber, and was mounted on an end wall, centered, with its top surface $5.2 \mathrm{~cm}$ above the grid floor. A 30-g downward force was required to record a leverpress. To record a lever-bite response, a force of $200 \mathrm{~g}$ between the upper and lower surfaces of the lever was required.

An electromechanical relay was attached to the metal wall on the outside of the chamber $5 \mathrm{~cm}$ above the lever to provide a feedback "click" contingent upon either a leverpress or a lever bite. The chamber was illuminated by a $7 \frac{1}{2}-\mathrm{W}$ houselight mounted $7 \mathrm{~cm}$ above the lever. Electric shocks, with intensity of $3 \mathrm{~mA}$ and duration of $.5 \mathrm{sec}$, were produced by a BRS Foringer shock generator (Model SG 901) and scrambler (Model SC 903). The chamber was contained in a ventilated sound-attenuating enclosure; white noise was supplied, and the control equipment was in a separate room. Leverpresses, lever bites, and shocks were recorded throughout all conditioning sessions.

\section{Procedure}

The basic avoidance procedure was of the kind devised by Sidman (1953), with a shock-shock (SS) interval of $5 \mathrm{sec}$ and a response-shock (RS) interval of $20 \mathrm{sec}$. By our initial plan, lever biting was to be the avoiding response for some animals and leverpressing was to be the avoiding response for others, providing for detailed comparisons between animals on the two conditions. Accordingly, three rats, B-2, B-3, and B-4, were exposed to the procedure in which only biting could postpone shocks. This schedule was in effect for one 360 -min training session and three 100-min sessions conducted on consecutive days. None of the three animals displayed any lever biting. The animals were observed to engage in biting behavior but it was entirely directed toward the grid floor and the animal's feet. Foot biting was of such a severe degree that conditioning with this procedure was impractical. [The relatively intense, 3-mA shock used throughout the work reported here was chosen to permit comparison with data from Pear et al. (1972).] In light of this preliminary finding, the procedure was changed to the one which follows, and the animals initially exposed to this "biteonly" condition were discontinued. The subsequent experiment consisted of two phases, each conducted during daily 100-min sessions.

Phase 1. The basic procedure remained unchanged, with an SS interval of $5 \mathrm{sec}$ and an RS interval of $20 \mathrm{sec}$. However, during this phase both lever biting and leverpressing could postpone shock. After responding appeared stable with the SS interval of $5 \mathrm{sec}$, as indicated by no systematic change over five consecutive sessions, the SS value was increased to $10 \mathrm{sec}$ and, after stability was reached on the 10 -sec value, finally increased to $20 \mathrm{sec}$, where it remained for the duration of Phase 1 . The RS interval remained at $20 \mathrm{sec}$ throughout Phase 1.

Phase 2. Subjects were exposed to a procedure identical to Phase 1 with a single exception. There were no longer any scheduled consequences for leverpress responding; during Phase 2 only lever biting could postpone electric shocks. At the start of Phase 2, the SS interval was $5 \mathrm{sec}$ and increased to 10 , and subsequently $20 \mathrm{sec}$, as in Phase 1 . The RS interval remained at $20 \mathrm{sec}$ throughout Phase 2.

\section{RESULTS}

Figure 1 shows that during Phase 1, where leverpressing and lever biting could postpone shock equally well, only leverpressing was reliably produced and maintained.
PHASE I. BITE OR PRESS AVOIDS

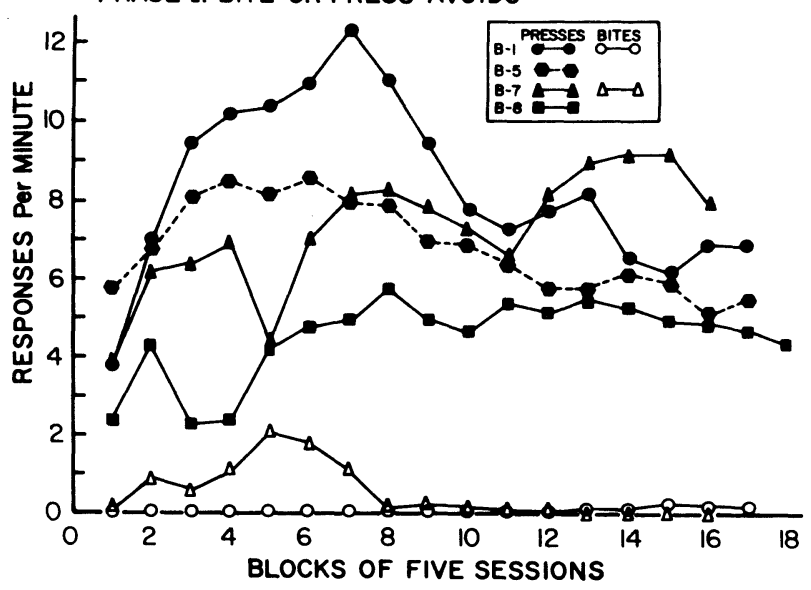

Figure 1. Rates of leverpressing and lever biting for each of four rats during Phase 1 , in which both of these responses could postpone shocks. Filled symbols indicate leverpressing for all animals. Open symbols indicate lever biting for the two animals that displayed biting on this procedure. Each data point represents a mean taken over five consecutive 100-min sessions.

All four rats acquired this response, and while response rates varied substantially across animals during the early weeks of training, responding eventually stabilized at rates ranging between 4 and 9 responses/min. In contrast, lever biting was not reliably produced or maintained by this procedure. For two of the rats (B-5 and B-8), no lever biting was detected during Phase 1, and hence no biting data are plotted for these animals in Figure 1. The rate of biting for Rat B-7 increased and then decreased over the early weeks of conditioning. These changes bore no systematic relation either to shock rates or to rates of pressing. Rat B-1 occasionally bit the lever, but seldom more than 20 times in a 100-min session.

During Phase 2, where only lever biting could postpone shocks, two of the four rats, B-1 and B-7, reached substantial rates of lever biting (Figure 2), stabilizing at 5 to 7 responses/min. Rat B-8 showed lower biting rates, but these were also fairly stable, at 1 to 2 responses/min. Rat B-5 showed no lever biting.

Phase 2 constituted an extinction procedure for leverpressing that had been maintained in Phase 1. As shown by the filled symbols in Figure 2, the rates of pressing for Rats B-5 and B-8 decreased quickly to negligible levels, and the rate for Rat B-7 also decreased systematically, but to intermediate levels. For both Rat B-7 and Rat B-8, the rates of lever biting dropped below the rates of leverpressing, while for Rat B-5, both biting and pressing rates were at zero by the end of the experiment. The rate of pressing for Rat B-1 first dropped, while the biting rate was increasing, but then increased, to be maintained at levels far in excess of those maintained during Phase 1 and far in excess of this rat's shock rates, as shown in Figure 3.

Figure 3 , showing shock rates for all rats in both Phase 1 and Phase 2, provides a comparison of the rats' 


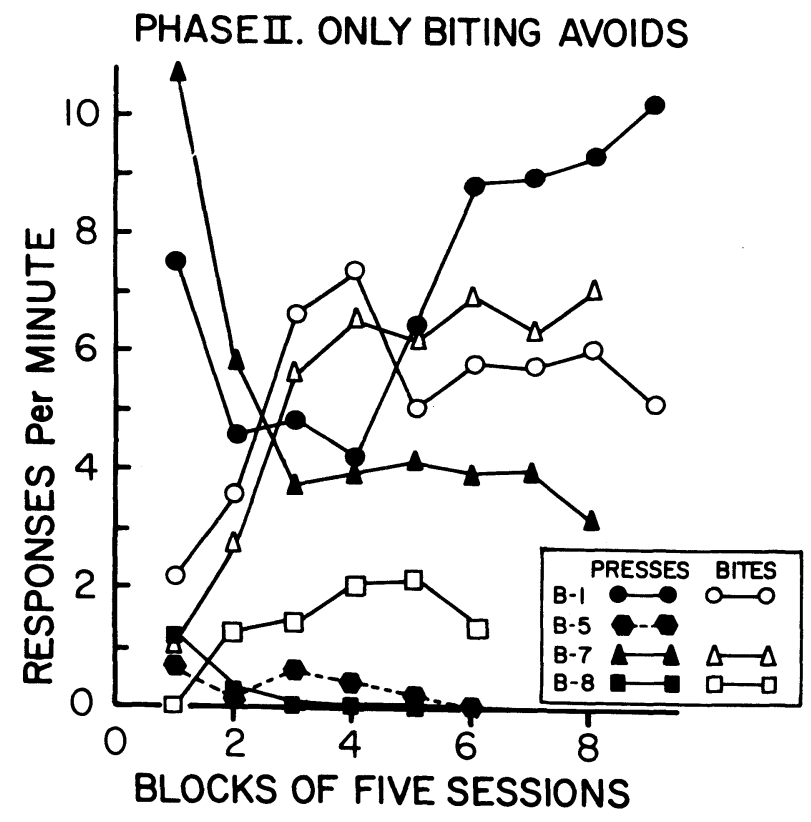

Figure 2. Rates of leverpressing and of lever biting for each of four rats during Phase 2 , in which only lever biting could postpone shock.

proficiency of avoidance on the two procedures. Clearly, each rat took more shocks when biting was the required response than when both pressing and biting could postpone shocks. This relation holds both for the final levels of performance on each procedure and for a session-by-session comparison of acquisition on the two procedures. That is, for more than $92 \%$ of the sessions (92\% for B-7, $93 \%$ for B-8, $95 \%$ for B-1, and $100 \%$ for

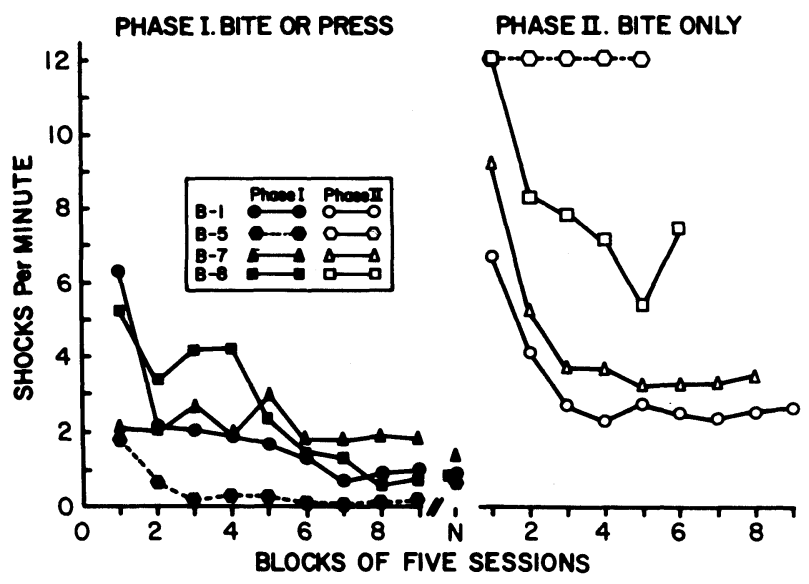

Figure 3. Shock frequencies for four rats. The filled symbols are from Phase 1 , in which both biting and pressing could postpone shock. The first 45 sessions are represented, with means taken over successive blocks of 5 sessions. The mean for the final five sessions of Phase 1 is also shown, denoted as " $N$," since the number of sessions varied slightly for different animals. The open symbols are from Phase 2, in which only lever biting could postpone shock.
B-5), shock rates were higher in the nth session of Phase 2 than in the nth session of Phase 1.

\section{DISCUSSION}

Phase 1 of the present experiment provided an initial direct comparison of lever biting and leverpressing as avoidance responses. Both a leverpress and a lever bite could serve as the effective operant, but only leverpressing was consistently produced and maintained by the conditioning procedure. This outcome, along with the earlier failure of a "bite-only" procedure to establish lever biting as an avoidance response in three naive animals, indicates that lever biting was not a predominant response in the present situation. From this, the conclusion least damaging to interpretations of avoidance in terms of SSDRs is that lever biting was not an SSDR in the present experimental situation. However, while preserving an SSDR interpretation, this conclusion points out a serious weakness in that interpretation: NO principles have been supplied for predicting, in detail, the forms that the defense reactions will take in a particular situation. Without such principles one must either proceed on a post-hoc basis, as has usually been done, or one must look to previous studies to identify the specific defense reactions for a given situation. The latter approach was taken in the present case and the choices seemed straightforward. A standard "arbitrary" avoidance procedure involves electric shock as well as leverpressing, and shock-induced biting is a reaction that has been extensively studied. Hence, biting and pressing are obvious choices when shock is the aversive stimulus. In some studies of shock-induced biting, the animals have been constrained in such a way that orientation toward the designated biting target was ensured (e.g., Azrin et al., 1968). We elected not to constrain our rats in this way, since the results would have limited applicability to the less constrained avoidance situations, in which a role of defense reactions has usually been invoked. Our own informal observations, as well as those by Azrin et al. (1967), suggested that sufficient biting would occur without such constraints They reported: "We have often noted that a rat or monkey will bite a projecting object in the enclosure during the initial stages of shock-avoidance conditioning." After describing a monkey's transition from biting, to grasp before biting, to leverpressing, they stated that "Visual observation of other monkeys and rats has revealed many similar instances in which biting was the initial reaction to the response lever during shock-avoidance conditioning" (Azrin et al., 1967, pp. 144-145).

The experiment by Pear et al. (1972), who studied lever biting during the conditioning of leverpress avoidance, provided further, more specific guidance for the present work. In duplicating most features of their experimental situation, we had expected that in our preliminary "bite-only" procedure a substantial amount of biting would occur, directed at the lever. Hence, the complete lack of lever biting in all three rats on this procedure was an unexpected outcome. However, close examination reveals that the present results were not entirely inconsistent with the findings of Pear et al. They reported that three of seven rats did not bite the lever. If one includes the four rats in Phase 1 of the present experiment, the proportion is similar to that found by Pear et al. The fact that we found lever biting only when there was an initial avoidance contingency for leverpressing suggests that this contingency may serve to make the lever a focus of biting. Both our findings and theirs are, of course, affected by the degree to which biting was directed at objects other than the lever.

Putting aside its imprecision for predicting the initial occurrence and focus of a biting response, the SSDR hypothesis is challenged directly by the present data for rats that did show some lever biting. If avoidance were mainly selection of prepotent defense reactions, one would expect rapid predominance of more intense bites once they started to occur at all in Phase 2 of the present experiment. Instead, the three animals whose 
lever biting was maintained by the "bite-only" procedure in Phase 2 avoided less effectively than they had avoided in Phase 1, where leverpressing was an allowable response. That is, they achieved lower shock rates by leverpressing in Phase 1 than by biting in Phase 2. An SSDR theorist might counter by suggesting that there may have been biting at force levels less than our criterion of $200 \mathrm{~g}$ that either were undetected or were recorded as leverpresses. Regarding this, it should be noted that our force requirement for registering bites was conservatively small; Pear et al. (1972) used a criterion more than five times as great. Since they found substantial amounts of biting with a criterion of $1,050 \mathrm{~g}$, it seems that bites of at least $200 \mathrm{~g}$ should have been readily selected out by the avoidance contingency.

In sum, the present results clearly suggest that biting cannot be categorically defined as an innately predisposed, easily acquired avoidance response to be contrasted with the "arbitrary" leverpress. To the extent that they predicted otherwise, interpretations of conditioning phenomena in terms of biological constraint or predisposition have not been sufficiently precise for other than post-hoc explanation.

\section{REFERENCES}

Azrin, N. H., Hutchinson, R. R., \& Hake, D. F. Pain-induced fighting in the squirrel monkey. Journal of the Experimental Analysis of Behavior, 1963, 6, 620.
Azrin, N. H., Hutchinson, R. R., \& Hake, D. F. Attack, avoidance, and escape reactions to aversive shock. Journal of the Experimental Analysis of Behavior, 1967, 10, 131-148.

Azrin, N. H., Hutchinson, R. R., \& Sallery, R. D. Painaggression toward inanimate objects. Journal of the Experimental Analysis of Behavior, 1964, 7, 223-228.

Azrin, N. H., Rubin, H. B., \& Hutchinson, R. R. Biting attack by rats in response to aversive shock. Journal of the Experimental Analysis of Behavior, 1968, 11, 633-639.

Bolles, R. C. Species-specific defense reactions and avoidance learning. Psychological Review, 1970, 77, 32-48.

Bolles, R. C. Species-specific defense reactions. In F. R. Brush (Ed.), Aversive conditioning and learning. New York: Academic Press, 1971. Pp. 183-233.

Hutchinson, R. R., Azrin, N. H., \& Hake, D. F. An automatic method for the study of aggression in squirrel monkeys. Journal of the Experimental Analysis of Behavior, 1966, 9, 233-237.

Pear, J. J., Moody, J. E., \& Persinger, M. A. Lever attacking by rats during free-operant avoidance. Journal of the Experimental Analysis of Behavior, 1972, 18, 517-523.

Sidman, M. S. Avoidance conditioning with brief shock and no exteroceptive warning stimulus. Science, 1953, 118, 157-158.

Ulrich, R. E., \& Azrin, N. H. Reflexive fighting in response to aversive stimulation. Journal of the Experimental Analysis of Behavior, 1962, 5, 511-520.

(Received for publication December 7, 1977.) 